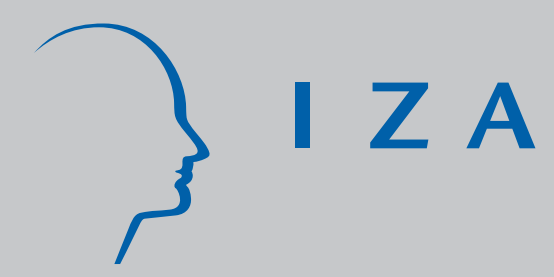

IZADP No. 3979

Cream-Skimmer or Underdog?

Labor Type Selectivity, Pre-Program Wage, and Rural Labor Training Program Outcome

Yiu Por (Vincent) Chen

J anuary 2009 


\title{
Cream-Skimmer or Underdog? Labor Type Selectivity, Pre-Program Wage, and Rural Labor Training Program Outcome
}

\author{
Yiu Por (Vincent) Chen \\ DePaul University and IZA
}

Discussion Paper No. 3979

January 2009

\author{
IZA \\ P.O. Box 7240 \\ 53072 Bonn \\ Germany \\ Phone: +49-228-3894-0 \\ Fax: +49-228-3894-180 \\ E-mail: iza@iza.org
}

\begin{abstract}
Any opinions expressed here are those of the author(s) and not those of IZA. Research published in this series may include views on policy, but the institute itself takes no institutional policy positions.

The Institute for the Study of Labor (IZA) in Bonn is a local and virtual international research center and a place of communication between science, politics and business. IZA is an independent nonprofit organization supported by Deutsche Post Foundation. The center is associated with the University of Bonn and offers a stimulating research environment through its international network, workshops and conferences, data service, project support, research visits and doctoral program. IZA engages in (i) original and internationally competitive research in all fields of labor economics, (ii) development of policy concepts, and (iii) dissemination of research results and concepts to the interested public.
\end{abstract}

IZA Discussion Papers often represent preliminary work and are circulated to encourage discussion. Citation of such a paper should account for its provisional character. A revised version may be available directly from the author. 


\section{ABSTRACT \\ Cream-Skimmer or Underdog? Labor Type Selectivity, Pre-Program Wage, and Rural Labor Training Program Outcome}

The mismatch between laborer's abilities and the target subject of the training program is one of the most primary concerns for a labor training program. The ability of different workers may significantly affect the outcomes of a labor training program. The objective of this paper is to look at the incentive of labor to enter the program using data of a pilot study at Zhejiang province in China. This paper shows that the average distance of a training center in a village, and the active labor proportion in a family are the core instruments that influence participation of laborers in the rural labor training program. It suggests that rural laborers enter the training program due to the availability of abundant labor in a family, and the convenient conveyance cost to the training center. The "Ashenfelter's dip," a pre-program wage drop, on the other hand may induce workers of higher caliber to enter the training program and cause the "cream-skimming" effect to training program. The traditional view of "opportunity cost" to enter a training program is extended by the result of cream skimming and training and can be used in revising the future design of rural labor training program. Putting the cream-skimming effect and the training issues together, a better accountability and governance of the training program which actively takes into account of rural laborer needs may be called for.

JEL Classification: $\quad \mathrm{P} 36, \mathrm{O} 15, \mathrm{J08}, \mathrm{J43}, \mathrm{J48}, \mathrm{I38}$

Keywords: rural labor training, labor migration, labor market policy, poverty alleviation, sunshine program

Corresponding author:

Yiu Por (Vincent) Chen

School of Public Services

DePaul University

25 E. Jackson Blvd

Suite 1250

Chicago, IL 60604

USA

E-mail: ychen16@depaul.edu

\footnotetext{
* This research is supported by The Overseas Young Chinese Forum (OYCF) -The 1990 Institute Research Fellowship, the DePaul University's Competitive Research Grant, and DePaul University's Summer Research Grant. The author would like to thank the Department of Education and Training at the Labor Bureau, PRC, Professor Nansheng Bai, Professor Zhong Zhao for their support of this study.
} 


\section{Introduction:}

The main reason of getting concerned about labor training program is the proper matching of the program and the type of labor enrolling in it. The main objective of the rural labor training program is to train those laborers who are able to earn a higher income after completion of training. Theoretically speaking, there are generally three types of labor in a training program. The ideal type of labor to be trained are those who can obtain higher income after program and their decision to enter the program is depends on the likelihood that they can make themselves available to the program (from their rural family work) and the transaction cost to enter the program. The usual problems that a labor training program may generally face are related to the two kinds or class of unwanted trainees who enter the program. The first of this kind is the under-dog, with a lower ability than average labor, is not the target subject of the training program. These laborers may not match with the level of the training program and may not benefit from the program. The second class or the cream-skimmer laborer who enters the training is of a higher caliber than the average labor and is not the targeted subject of the training program. The laborers with a higher caliber enter the program to take advantage either of the program's signaling effect or their marketing facilities for better career. This may affect the utility and productivity of the program because the higher resultant wage earned by the laborer is not created as an effect of the program, but the workers' personal ability. This also sets a trend in the training field of high caliber workers to "crowd out" the target workers by reducing their possibility of entering the program.

The Ashenfelter's dip or the pre-training wage drop (pertaining to the lower than comparison group) may also be an important factor for the selection of the training program apart from the problem faced due to labor type selectivity (Ashenfelter, 1978). In the perspective of “opportunity cost”, training participation may be increased by a pre-program wage drop because of the lower wage forgone during the training period. This means that, the larger the wage deterioration, the lower the opportunity cost of training and the higher the probability of an individual entering a training program (Ashenfelter and Card, 1985; Heckman, 1978; Heckman and Robb, 1985). This paper combines the Ashenfelter's dip with the labor type problem and extends the view of the Ashenfelter's dip into the case .It reflects that the laborers who are 
higher than average wage laborers enter the rural labor training program when they face a downturn in income. A downward spiral in higher wage income workers may inspire them to enter the program with the objective of obtaining a better job later and thus accelerate the cream skimming effect. However, in rural labor training, the motivation of labor may not be achieved due to the "opportunity cost", since these types of rural training program are usually short and may not incur loss in income. Instead, a downward spiral of wage itself may be sufficient enough to induce the labor for job training because of an expected concern for increase in future income.

This paper, therefore, seeks to combine the pre-program wage effect and the selection problem of difference in labor type into a rural labor training program. The primary aim of this paper is to first identify the trained individual characteristics; then explore the effect of training and labor type selectivity to the rural labor training program outcomes. This study is very important for evaluating training program evaluation projects, because a wrongly identified subject towards orientation of the training program may impinge on the validity of program outcomes. I will use a pilot study from a county level city at Zhejiang province to study the program monitoring issues of "Sunshine Program," (Yangguang gongcheng) the current rural labor training program in China.

The "Sunshine Program," a new labor training campaign, was initiated by the central government of China in April 2004 as a new measure of alleviating rural poverty. The aim of the rural labor training is to equip peasants with professional skills and transform them into laborers to work where there is a need. This program is perhaps the largest in terms of scale of training in human history. The objective of this program is to train thirty-five million rural workers within the 21 designated provinces and autonomy zones by 2010 (Agricultural Department, 2004). This study is important because, to obtain a successful outcome of such a large scale program, a proper matching between labor type and the program is very essential.

The major findings of this paper are to highlight the following observations: Firstly, the trained individuals show the following features- 1) lower out-migration experience 2) more female proportion and 3) higher proportion of workers in a family, which suggest that the rural laborers who enter the program are 
relatively less competitive. Secondly, training significantly increases not only the trained individuals' income but also explains training participation significantly by showing the relation between active labor proportion within a family and average distance to the local training center. This has been shown by using the Instrumental Variable (IV) regressions. These two IVs signify the availability of an individual to a program and the transaction cost to training, respectively. I have further used three additional IVs on preprogram wage drops that represent the "Ashenfelter’s dip," to examine the problem of "opportunity cost” to training and found no evidence of an individual's participation responding to this reason. Instead, a drop in wage may induce higher income workers to enter into a training program, thus resulting in the "creamskimming" effect through expected income drop. The IV regressions further show that both "training" and “cream-skimming” as instrumented variables have positive effect to income change. These results call for a better monitoring system in the training program because the governance of trainee recruitment may be a problem.

The paper commences with a brief outline of the need of a rural labor training program in China as an alternative means to poverty alleviation. A description of the general organizational structure of the Sunshine Program is presented in section 3, which is followed by a section presenting the pilot study in Zhejiang to evaluate the effect and contribution of labor training and labor type selectivity towards the program outcome. The concluding part of the paper deals with a discussion on the effectiveness of labor training programs and its implications. 
2. Rural labor training, and Policy Implications of the Rural Labor Training

Why is rural labor training a vital need of the present day? Rural labor Training, presently can be treated as one of the ways of poverty alleviation. This program, though may not provide a complete solution to the rural unemployment problem, but might offer an opportunity to some of the trainees to enter their first temporary work contract just on completion of their training. But the impact of this program on long-term employment may not be ignored (Autor, 2001; Autor and Houseman, 2005). The key development focus for the central government of China has been the underdeveloped rural economy and a high proportion of rural population. These issues were responsible for the spontaneous upsurge of rural-urban labor migration since the reform in the 1980's. These rural-urban immigrant flows have been once labeled as "blind-flow" because of the low level of attainment in education and skills in the urban labor market. According to Arthur Lewis, the "unlimited supply of rural labor" will drive down the urban wage level of labor (Lewis, 1954). However, in reality, the urban labor wage has been driven down due to the "local competition for jobs by the migrants”, and which was directly related to -the low level of skill of the rural-urban laborer, the nature of jobs that they have access to, and the urban labor market structure (given the hukou system and other discrimination policies by the governments at different levels and urban public). As a result, a tough competition usually developed between the migrant workers themselves but not with urban residents. The low level of skill in migrated labor constitutes a mismatch in labor market and drives down the wage structure of migrants but not that of urban residents. Consequently most rural-urban migrant families earn an amount that barely equals the rural income and hence they are unable to improve their living conditions. The persistence of this problem may lead to the emergence of ghettos and slumps in the future. These rural laborers often have less incentive to upgrade their own skill due to a labor market mismatch. In this respect, the inability to increase rural laborers' human capital will be translated into rural-urban inequality as urban areas grow much faster than most of the rural areas in China. Determining how the government can help to reduce the rural-urban inequality has become a recent burning issue. 
Traditional Chinese poverty alleviation programs have always been concentrated on provision of basic needs or farming-related investments. Although these programs help peasants (who are usually poorer than urban residents) to increase agricultural productivity, they do not provide them with alternatives to seek better use of their labor, at least at the natural level. The labor training program in this study is different from other job training programs. This study focuses on rural residents who are low in skill and are nonmigrant. ${ }^{2}$ The objective of the program is to enhance their skills and increase the number of skilled ruralurban migrant that can cater to the demand of industries. In this regard, this program may take the initiative to provide a way of diversifying rural labor inputs.

\section{A Brief description of Sunshine Program's Structure, and Program Organization}

The Sunshine Program is a rural labor training program which aims to increase the quality and quantity of rural-urban migrant labor. The program covers 26 provinces (city and districts) with Xijian production army and headquarters of Heilongjiang agricultural development department. (Sichuan agricultural department, technological education division, 2004).

The program mainly focuses on those with a potentiality to benefit from the rural labor training. The target of this program is to enable at least eighty percent of these trained peasants to transfer to labor and find jobs in other sectors as well. In other words, the program focuses not only on those peasants who are living in poverty, but introduces a strategy to reduce the pressure of surplus labor in the rural areas, and supply trained labor force with mostly basic skills to the industries in need .

The target of training size is decided at the provincial level, upon approval of the central government. The training duties are then shared with the local level of program organization. The participatory population at the training in 2004 and 2005 was 2.5 million each year. The target of training rural population under this

\footnotetext{
${ }^{2}$ And most of the countries focus on three types of training program:

1. $\quad$ Retaining long-term unemployment (over 12 months)

2. $\quad$ Retaining displaced workers, such as mass enterprise/industrial restructuring.

3. Training of young people (often focus on the school drop-outs). O’Leary et. al. (2001)
} 
program annually from 2006 to 2010 is 6 million. The total number of rural population that would receive training from 2004 to 2010 will be 35 million. (Agricultural Department, 2004)

This training program receives financial support both from the central and the local government, though the local governments are the major contributors. If the central government contributes 100 Yuan, the local government will contribute no less than 100 Yuan to make the program work. The basic focus lies on those provinces which has the largest- number of rural-urban migration, agricultural production, or concentration of rural poverty. The way of subsidies can be direct reduction of training or tuition fees or through provision of labor training vouchers. Labor training vouchers must be distributed directly from the local level of finance department or Sunshine Program offices to peasants, allowing peasants the opportunity to choose the training institutions themselves (Agricultural department, PRC, 2005a, article 11). However, financial support to rural labor training will not include those who are on-job trainings (2005a, article 9).

The duration of the program is usually around 15-90 days, depending on the kind of training provided. Local governments can develop their own training program, program length, type and kind of jobs to be included in the program, according to their local labor market conditions and requirements. These training can be provided either by government institutions such as vocational schools, or by private organizations at the local level, according to the regulations. However, the standard of labor training should match with the labor demands. Recently the central government identifies housekeeping, restaurant services, hotel services, massage, construction, and manufacturing as large demand professions (2004b, article 5). Also, a series of supplementary labor program services had also been introduced: labor right protection, labor law, basic knowledge of living in the city, job searching services (Agricultural Department, 2005a, article 2) which appear as subsidiary trained labor services providing support to the existing labor market. 
4. The Effect of Labor Training to Laborer's Income Change: Evident from a pilot study

In this section, the program's impacts on trained rural labor have been focused upon using findings from the pilot study in July 2005 at a county level city in Zhejiang province. The pilot study in Zhejiang was conducted in July 2005. The focus of the survey is the labor mobility and the effect of rural labor training at Zhejiang province. Zhejiang was chosen because it is one of the earliest provinces to provide systematic rural labor training. In particular, the county level city in this survey is the first one that implemented the labor training program as a pilot program for the central government since 2003. The name of the county level city would be kept anonymous. The county level city was chosen by the central government because it was one of the poorest county level cities at Zhejiang province which is located at the western part of Zhejiang. I use hierarchical random sampling to choose two counties in the city and then three villages as random sample for low, medium, and high-income village groups within each county. I then use the systematic random sampling at the village level, in which I randomly select one household out of every five households in each village selected from the household registration book provided by the village secretary. The total number of valid household level questionnaires is 274.44 households reported received training in 2003 and 2004 (when the pilot program of the Sunshine program began).

In the following sub-sections, , I will focus on the basic characters of trained and non-trained workers from the data and then generate the hypothesis from these observations below (see other supplementary data descriptive statistics at Appendix A.) Methodology and identification strategy will be followed in the second sub-section. I will then present the findings from the regression results of our pilot study in the last sub-section.

4.1 An exploration of the survey data and hypothesis: 
Table 1 shows the distribution and number of households surveyed. Since workers may have already migrated to work in other places, the head of each selected household was surveyed for the information. We asked the head of the household to identify the most significant migrant worker in the household by his contribution to the family. We only consider the wageworkers in this paper because it is very difficult to differentiate individual efforts and outcome in family farm production. We then enquired about the history of the previous five years of the migrant worker since 2001. We queried in detail about working hours, holiday, wage information, and remittance amount over that five years period, in addition to household background information.

Table 1: Basic comparison between the trained and non-trained workers

Treated area

\begin{tabular}{|c|c|c|c|c|c|}
\hline Variable & No. of Obs. & Mean & Std. Dev. & Min & Max \\
\hline \multicolumn{6}{|c|}{ Non-trained } \\
\hline ln(hourly wage) & 483 & 1.41 & 0.53 & 0.2 & 4.2 \\
\hline Migrant sex & 1056 & 0.80 & 0.40 & 0.0 & 1.0 \\
\hline Migrant age & 1056 & 33.06 & 9.54 & 17.0 & 64.0 \\
\hline $\begin{array}{l}\text { Migrant martial status } \\
(1=\text { single, } 2=\text { married) }\end{array}$ & 1056 & 132 & 0.47 & 10 & 20 \\
\hline Migrant's education year & 1044 & 8.53 & 2.64 & 0.0 & 15.0 \\
\hline $\begin{array}{l}\text { Experience at migrant worker } \\
\text { (year) }\end{array}$ & 1056 & 7.38 & 5.42 & 0.1 & 30.0 \\
\hline Family size & 900 & 3.91 & 1.24 & 1.0 & 10.0 \\
\hline $\begin{array}{l}\text { Family income level in a village } \\
\text { ( } 1 \text { is highest and } 5 \text { is the lowest) }\end{array}$ & 1082 & 3.12 & 0.95 & 1.0 & 5.0 \\
\hline \multicolumn{6}{|c|}{ Trained } \\
\hline ln(hourly wage) & 84 & 1.37 & 0.65 & -0.3 & 3.0 \\
\hline Migrant sex & 192 & 0.47 & 0.50 & 0.0 & 1.0 \\
\hline Migrant age & 192 & 34.06 & 10.44 & 18.0 & 55.0 \\
\hline $\begin{array}{l}\text { Migrant martial status } \\
\text { (1=single, } 2=\text { =married) }\end{array}$ & 192 & 1.28 & 0.45 & 1.0 & 2.0 \\
\hline Migrant's education year & 186 & 8.00 & 3.09 & 0.0 & 13.0 \\
\hline $\begin{array}{l}\text { Experience at migrant worker } \\
\text { (year) }\end{array}$ & 186 & 4.67 & 4.04 & 0.2 & 17.0 \\
\hline Family size & 174 & 3.93 & 1.06 & 3.0 & 10.0 \\
\hline $\begin{array}{l}\text { Family income level in a village } \\
\text { ( } 1 \text { is highest and } 5 \text { is the lowest) }\end{array}$ & 202 & 2.87 & 0.61 & 2.0 & 4.0 \\
\hline
\end{tabular}

The number of observations above is calculated from a five year individual level panel that each individual will have 5 observation if no missing occurred 
As shown in Table 1, trained workers in general are one year older in age and half year lower in average education years than the non-trained workers. Apart from that their average work experience as migrant workers are over 50 percent lower than the non-trained workers. In average, the trained workers have work experience of only 4.67 years, while the non-trained workers have an experience of 7.38 years! However, the trained workers' family income level in average (2.87) is higher than the non-trained workers' family (3.12). Putting all these noticeable characteristics together, the preliminary assessment of workers who received training seems reasonable, since they have less migration experience, are older in age, and lower in education, which makes them the target subject of this rural labor training program.

Certainly, policy makers would like to implement their training program effectively by attracting the correct type of labor to enter the program. Perhaps there are many reasons for an individual to enter the training program. The classical case of Ashenfelter's dip is that, a lower (than the comparison group) pretraining wage may reduce a worker's lower opportunity cost to training (Ashenfelter, 1978: 52). ${ }^{3}$ In this regard, a downward spiral in higher wage income workers may opt them to enter the program for a better job later and accelerate the cream skimming effect. Thus, it is important to understand if the worker entering the program is a cream skimmer or an underdog. Figure 1 compares the average hourly wage over the course of the five years since 2001. The upper left and lower left graph are for the non-trained and trained female respectively, while the upper right and lower right graph are for the non-trained and trained male. The general pattern shows that there is a gap in wage between genders.

\footnotetext{
${ }^{3}$ Ashenfelter noted that trainees tend to suffer a sharp decline in earnings just prior to program entry. The "pre-program dip" undoubtedly reflects adverse economic circumstances that are, at least, partly responsible for the individual's decision to enter training. Knowing whether the pre-program level of earnings is transitory or permanent is critical for developing an appropriate statistical model to account for selection on unobservables.
} 
Figure 1: A comparison of average hourly wage by gender and training group (2001-5)

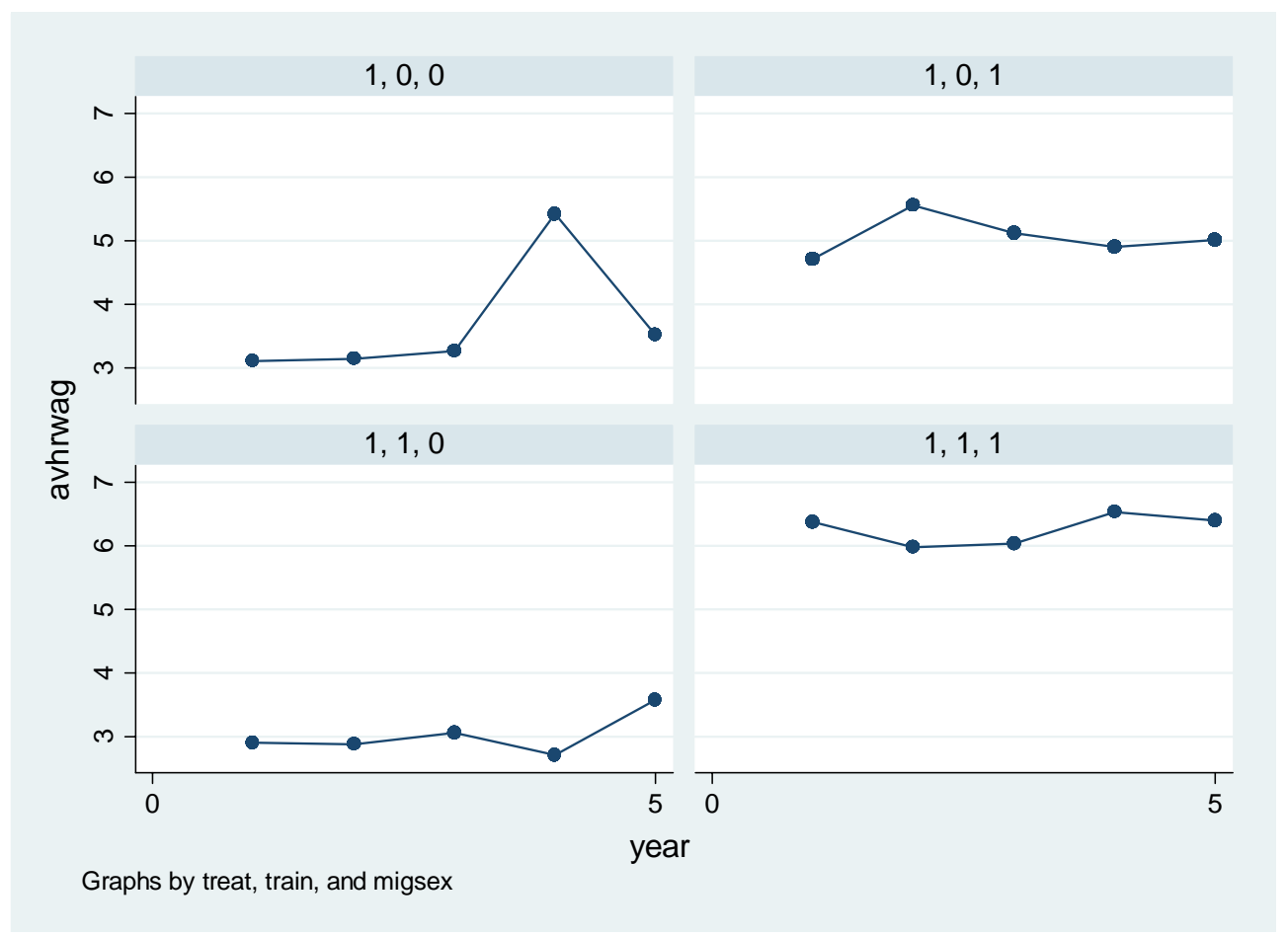

Note: for the above graph: all of the individual are in the treated area, City A. for the variable "train" signifying 0 for non-trained and 1 for trained. For the variable "migsex", 0 for female and 1 for male. Year 0-5 is 2000-5. The labor training program year is 2003 and 2004.

When comparing between the trained and non-trained female in Figure 1, except the jump in 2004 wage for non-trained female, it is observed that the wage are similar for the two groups. The trained female has a lower wage (under 3 yuan per hour) than the non-trained female (slightly over 3 yuan per hour) before the training period (before 2003). After training, their wage converged and the wage of the trained female seems to be surpass the non-trained female a little in 2005.

When comparing the trained and non-trained male in Figure 1, some interesting pattern emerged. Unlike the pre-program wage difference between the trained and non-trained female, the first surprising 
observation is that the trained male's income is around $30 \%$ higher than the non-trained migrant workers at 2001 even before their training (at 2003 or 2004). That is, the average hourly wage in 2001 and 2004 are below 4.8 yuan and 4.9 yuan for non-trained migrant and 6.3 yuan and 6.6 yuan for trained migrant. However, the upward trend of non-trained migrant and downward trend of trained migrant may be a factor for an individual to choose to enter the training program. This is because one may be more concerned about their future career when they experience downturn in their wage. Another interesting observation is that the trained migrants' income has bound back to the wage at 2001 after their training. However, the non-trained male migrant experiences a downward trend in their income since 2003. This is an interesting pattern that training may be helpful for those who experience a downturn in their career but may not be necessarily of lower ability than the non-trained. These observations as a whole are consistent with the literature in adaptive expectation theory and the Ashenfelter's dip that the larger the down turn of wage, the higher the possibility for an individual to enter the training program, even though these workers have higher ability. ${ }^{4}$ That may be the incentive for an individual who have experienced the downward trend in their career to enter into the training program. Our case, however, is different from the Ashenfelter's dip because now the higher wage laborer faces income downturn and enters the training program. This type of labor may consider training as an insurance for their future career when one faces their down turn of wage.

The research question now is that "does the training really have any effect on an individual's labor market performance, or is there someone with higher ability who wants to secure his career through the signaling effect of training when faced by the threat of lower income at the prior period”.

\footnotetext{
${ }^{4}$ Alternatively, when individuals experience an upward trend in their wage, they may likely to expect their wage to increase in the next period, and vice versa.
} 
4.2 Methodology, identification strategy, and variables

\subsubsection{Methodology and identification strategy}

As shown in Figure 1, the difference in the wage trends of trained and non-trained workers violates the assumptions of the traditional difference-in-differences approach. In order to investigate the training effect, I first run OLS regression and start with some preliminary analysis. I will then further analyse the reasons of program participation using Instrumental regressions. I hypothesize the change in hourly wage, which depends on an individual's personal observable ability and their social network to find their job. The regression equation at individual level is specified as follows:

$\ln W_{i v y}=T_{i} \phi+Z_{i v y} \beta_{v y}+\lambda_{y}+\alpha_{v}+U_{i v y}$

This basic model is a typical treatment for treated regression. Where $i$ indexes individual, $v$ indexes village, and $y$ indexes year. T is a dummy variable with " 0 " for non-trained workers and " 1 " for trained workers. This model has a full set of individual level specific covariates, $Z_{i v t}$, time effects, $\lambda_{t}$, a full set of village fixed effects, $\alpha_{v}$, and the error term. I am interested in the training coefficient, $\phi$. The idea of the equation is simply to investigate the training effect after observable individual covariates are controlled. Some slight variation of equation (1) will also be introduced subsequently in the following section.

The individual fixed effect is not applicable in this context as some of the independent variables are fixed over time, such as gender, age, and experience of migration. As a result, I will introduce year and village as fixed effect when appropriate in subsequent models. In order to make sure that the basic models are well specified, omitted variable tests will be introduced in the beginning of the OLS estimations at Table 3 in the 
next section. In addition, to obtain consistent estimation of covariant and capture the survey design effects, I will use jackknife method to deal with the survey design effect for all the regression.

The basic interest of this paper is to show how training affects income: Log hourly wage is the dependent variable that measures the outcome. I believe that the hourly wage is a much more accurate measure of the training outcome in China. It is because migrant workers usually work long working hours in a working day. They usually have fewer holidays than other urban area workers. Their holidays are usually concentrated around the spring festival. That may explain why trains are overcrowded during that period. However, hourly wage is not commonly documented in government level statistics and most of the survey studies. This is the reason why we make particular effort to collect data on hourly wage by adding various questions in the survey.

An individual participating in a training program may be motivated by some other effects. In this regard, labor training participation is a classical case that is usually correlated with other observed/unobserved characteristics. I will use two sets of instruments: family worker proportion to the family and average distance to training centers in a village. I use the family worker proportion to the family as IV for training participation because it may affect the availability of labor to work but may not be obviously related to the after training income. The average distance to training centers in a village can signify the transaction cost to participate in training which again may not be related to the income at the second stage of regression.

In order to test the hypothesis of “Ashenflter's dip” to the training program, I will use the wage difference of pre-program year and its past years as IV for participation. The idea is to observe whether an individual facing a downturn in income in the pre-program years may find herself induced to enter the training program for career signaling. To show the influence of the down turn of wage effect on labor training participation, I will use different specification of wage difference variables. In Ashenfelter's (1978) model, the pre-program earning histories play an important role in his estimation. As Ashenfelter (1978) noted, earning information contains an unobserved "fixed effect" for individual ability. Also, a transitory "earning dip" will make the results sensitive to the base year used to construct the first different model. 
With this idea in mind, at the pre-program year, 2002 and 2003, the first variable is specified as " 0 ” when current wage is at least as high as last year, and as " 1 ” when current wage is lower than last year. This formulation of the IV is similar to Angrist and Evan (1999) who used the indicator "1" for those parents having two children of the same sex and "0" otherwise in their first stage regression for having the third child. However the pre-program wage difference may not have immediate effect to training selectivity. I will also use the lagged wage difference as an alternative IV. In addition, I will use the real hourly wage difference from the pre-program year and its past year as IV for the program participation. I will also test the validity of these IVs in subsequent regression as appropriated.

To test the cream-skimming effect to income change, I use a variable "cream-skimmer" to represent that the individual has higher than average wage at pre-program period (2001 and 2002), in which "1" is an individual hourly wage which is higher than average hourly wage, or otherwise is "0." Recalling that a large gender gap in income has been shown in Figure 1, I therefore calculate the average hourly wage separately for different genders in this variable. As cream-skimmers are those labors with a higher than average ability who take advantage of the training program and signal their ability, cream-skimming effect thus reflects income change which is also a self-selection problem. Cream-skimming is then a sequential step when higher than average ability labors enter the training program. The common knowledge is that, that the higher ability workers are usually strongly associated with income. Therefore, we cannot use any variable to represent an individual ability as IV in the first stage since it will correlate with the second stage dependent variable, income. Alternatively, if the pre-program wage drop may affect the high income individual to enter the program, and is not related to the income changes, one can first use the pre-program wage drop as an IV for the "cream-skimmer" in the first stage regression. At the second stage regression, I can take into account the cream-skimming problem by regressing both instrumented "training participation" and "cream skimming effect" on income change. That is, I hypothesize that both training and cream-skimming occurred simultaneously and can be represented by IVs mentioned before that are not correlated with the second stage dependent variable. Since both "training” and "cream-skimming” will be included in the second stage regression, they can exert "control" over each other's effect on the income changes. 
There are also two sets of independent variables captured in $Z_{\text {ivy }}$ at equation (1) above. The first set of independent variables is observable individual abilities: such as individual educational year, age, gender, marital status, and years of migration experience. The second set of independent variables is "ways that a migrant finds job”. This signifies the migrant social network for job and is defined as 'discrete variables' as follows: $1=$ self, 2 =family members, 3 =relative, 4=friends, 5=villagers, $6=$ =worker heads, $7=$ =labor intermediation, 8=others. I will use the "ways that a migrant find job” as control variables.

\subsection{Regression Results:}

In this section, I will first show the instability of the training variable in the OLS regression. Then I will show the Instrumental variables regression labor type selection effect to income change in table 3 . Table 4 will extend the instrumental variable regression to "cream-skimming" effect on income change. Since training effect is the focus of the paper, I will concentrate the discussion on the training effects and its instrumental variables in this section.

Table 2 shows the regression results from The OLS regression. When looking across the column with different specification of the control variables, we first observed that the training effect is unstable: the first and last regressions show a negative value but the second regression shows a non-negative value, although the values are small and insignificant. One may be concerned about the existence of omitted variables that may bias the estimation; however, using higher order of independent variables independently in the regression, shows no rejection of the null hypothesis in the omitted variable bias test that there is no omitted variable at 10 percent level of confident interval. It is noted that the Ramsey test highlights the last regression's specification and is less likely to be misspecified. I will therefore use the two ways fixed effect model at the sub-sequent regressions. 
Table 2: OLS Estimation of Training Effect on Income Change

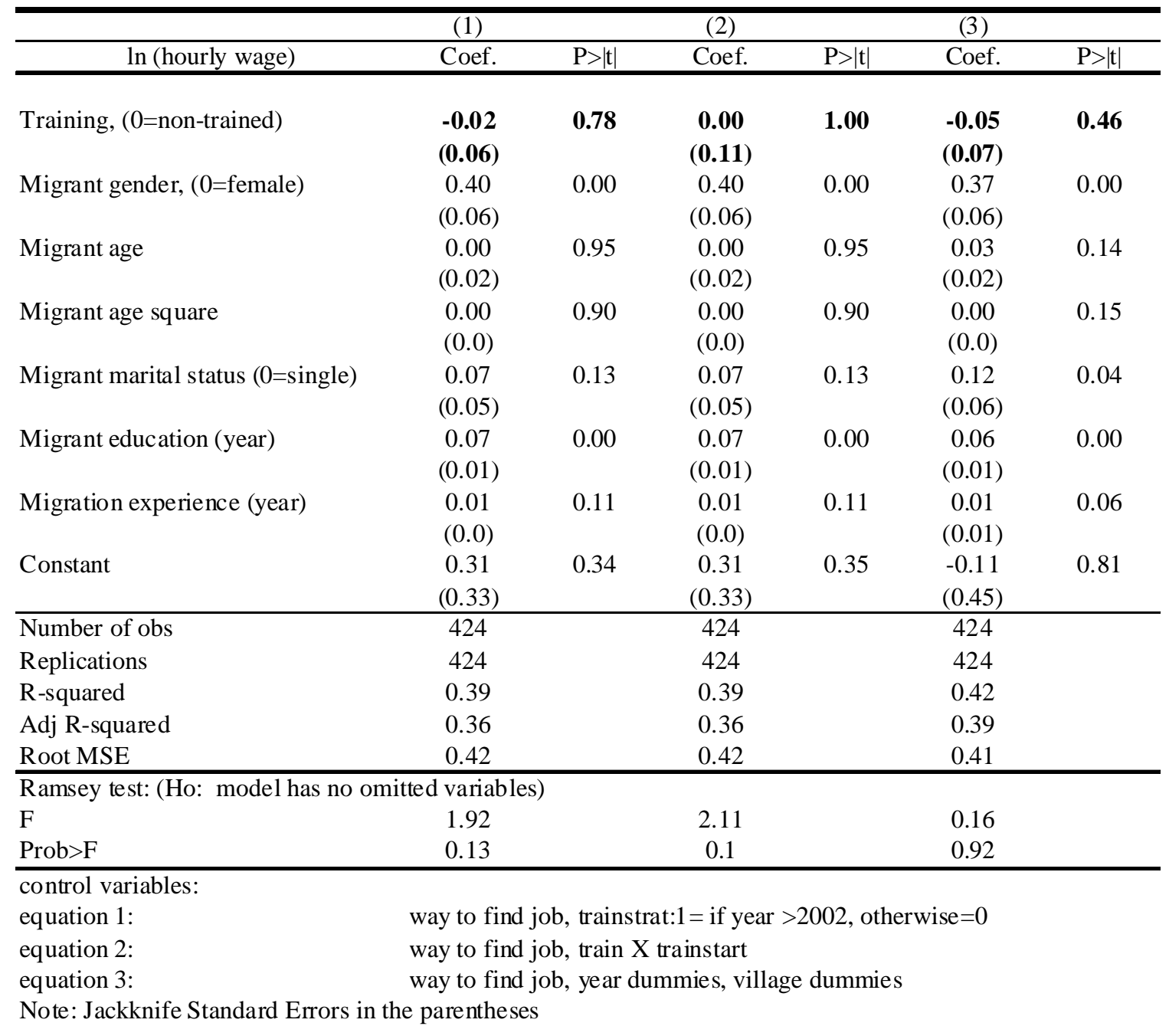

The estimated training coefficient, $\hat{\phi}$, provides an estimate for the average training effect from having trained, $\left[E\left(Y_{0 i} \mid T_{i}=1\right)-E\left(Y_{0 i} \mid T_{i}=0\right)\right]$. Thus $\left[E\left(Y_{0 i} \mid T_{i}=1\right)-E\left(Y_{0 i} \mid T_{i}=0\right)\right]=0$ only if the mean wage of workers with no training is equal to the mean wage of trained workers. However, workers who have not been trained may have better job prospect or expected opportunities since they had the upward trend before the training period at 2002. In this example, $\left[E\left(Y_{0 i} \mid T_{i}=1\right)-E\left(Y_{0 i} \mid T_{i}=0\right)\right]$ would be negative. Alternatively, if higher ability workers enter the program, $\left[E\left(Y_{0 i} \mid T_{i}=1\right)-E\left(Y_{0 i} \mid T_{i}=0\right)\right]$ would be positive. In either case, we can think of this as a selection 
bias in job training. This argument using the instrument variables described before clarifies that with the control of other independent variables in the second stage, the benchmark of first stage IV regression is specified by equation 2 .

$T_{i}=\operatorname{wkrprfm}_{i t}+$ avedist $_{i t}$

The IVs for the first regression is wkrprfm, active labor proportion in a family, which signifies the availability of the labor to participate in a program, and avedist, average distance of training center from workers' home, which denotes the transaction cost to participate in a program. In addition to the first regression's IV, the second, third, and forth regression introduce the "Ashenflter's dip" in various specifications.

$T_{i}=$ wkrprfm $_{i t}+$ avedist $_{i t}+$ wagdiff $_{i}$

The second regression added the wagediff, an indicator with " 1 "= wage lower than last year at the pretraining period and "0" otherwise.

$T_{i}=$ wkrprfm $_{i t}+$ avedist $_{i t}+$ L.wagediff $_{i}$

The third regression brings in L.wagediff , the lagged variable of the wagediff in the first stage of the regression.

$T_{i}=$ wkrprfm $_{i t}+$ avedist $_{i t}+$ wagedifva $_{i t}$

The fourth regression added the actual wage difference at the pre-program period which equals to current year wage minus last year wage in 2002 and 2003, respectively. Table 3 shows the IV regressions results with the four sets of IVs. 
Table 3: Instrumental Variable Regression on Training Effect to Wage Change

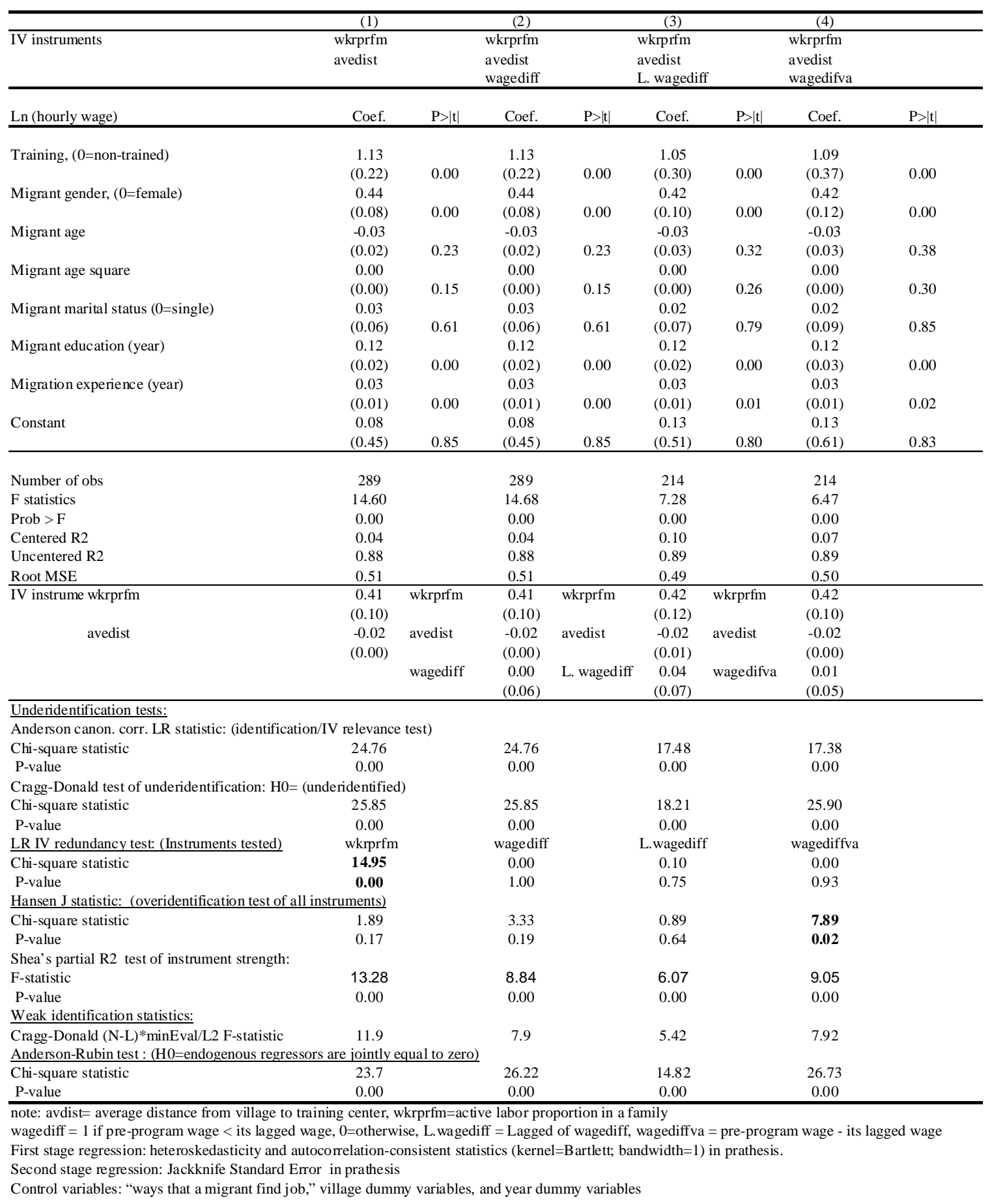


Table 3's IV regression shows a very different picture of training effect to income change. At the second stage of the regression, all instrumented training has significant effect to income changes at 1 percent level, suggesting that the labor type selection problem may exist in the program. Table 2's OLS regression shows that our system of equation is well-identified, still we need to ensure that our instruments are valid in that they are exogenous to the structural equation. First, we compute the Hansen-Sargan statistics to test the null hypothesis that the excluded exogenous variables, or the instrument variables, are not correlated to the regression error. I then further investigate the validity of each instrumental variable to the training participation. Except the last regression where the difference in pre-program wage value has been introduced in the first stage of regression, in all other specifications we cannot reject the null that the instruments are uncorrelated to the structural error term, suggesting that our system of equations is wellidentified. ${ }^{5}$ That is, the inclusion of the difference in pre-program wage value as IV is rejected by the Hansen-Sargan statistic. Indeed, as shown in the likelihood ratio redundancy test, the pre-program wage difference variables as instruments are redundant since the asymptotic efficiency of the estimation is not improved by using these pre-program wage difference variables from the second regression onward in Table $4{ }^{6}$ Thus, in term of pre-program wage drop, Table 3 shows no evidence of Ashenflter's dip in this training program study in general. IV regressions at Table 4 suggest that training participations are largely driven by the availability of active labor in a family and the transition cost to the training center. However the training effect may be over-stated without the control of the cream-skimmer effects at the second stage regression. Next section shows how cream-skimmers may affect income changes in this training program using the same sets of IVs.

\footnotetext{
${ }^{5}$ When I use the Cragg-Donald test I find strong evidence against the null that the system of equations is under identified (namely, that the matrix of reduced form coefficients has rank equal to $\mathrm{K}-1$, where $\mathrm{K}$ is the number of regressors). These results again confirm that our system of equations is well-identified. In order to ensure that the results are not affected by the well known weak instrument problem, we conduct Shea's (1997) partial R2 test and its associated F-statistic. The Shea's partial R2 is the "squared partial correlation" between the excluded instruments and the endogenous regressors. In all four specifications we find that the F-statistics are statistically significant and strongly rejects the null that there is no correlation between our instrumental variables and endogenous regressors, indicating that the IVs do not have a weak instrument problem. These test results can be obtained upon request.

${ }^{6}$ The statistic of a likelihood-ratio test based on the canonical correlations between the regressors and the instruments (with, and without) also shows that the instrument is redundant. Under the null that the specified instruments are redundant, the statistic is distributed as chi-squared with degrees of freedom=(\#endogenous regressors)*(\#instruments tested). Rejection of the null indicates that the instruments are not redundant.
} 
4.4 Cream-skimming effect to trainees' income change

In this section, I focus on the cream-skimming effect on trainees' income change using the pre-program wage difference variables and the “Ashenflter's dip” variables in last section as major IVs. Recall that the pre-program wage difference variables representing the "Ashenfelter's dip" do not significantly explain the "training participation" in last section. A drop in wage, however, may induce the "cream-skimmer" to participate in the program.

The essence of the "cream-skimming" as instrumented variable in the first stage regression is as follows: If “Ashenflter's dip” variables presented as IVs is associated with "cream-skimming” but is not related to the dependent variable, 'log hourly wage' in the second stage regression, then the IV is valid. Furthermore, with the control of training participation at the second stage regression, one can estimate the creamskimming effect on income change. With this argument, using the instrument variables described before, by the control of other independent variables in the second stage, the benchmark first stage IV regression is specified by equation 3 .

Cream $_{i}=$ wkrprfm $_{i t}+$ avedist $_{i t}+$ wagdiff $_{i}$

At Table 4, after the first OLS regression, other regressions are IV regressions with instrumented variables "training" and "cream-skimming." The IV regressions of "training" are specified in the last section. The "cream" at equation 3 represents the "cream-skimming" that the individual has higher than average wage at pre-program period (2001 and 2002), in which “1” is an individual hourly wage which is higher than the average hourly wage at the pre-program period, but is otherwise " 0 ." The IVs for the second regression is wkrprfm, active labor proportion in a family, which signifies the availability of labor to participate in a program, avedist, average distance of training center from workers' home, which denotes the transaction cost to participate in a program, and the wagediff, an indicator with " 1 "= wage lower than last year at the 
pre-training period and " 0 " otherwise. In addition to the training IV regressions specified at equation 2.1 to 2.3, the second, third, and fourth IV regression on "cream-skimming" also introduces the same set of “Ashenflter’s dip” in various specifications.

$$
\text { Cream }_{i}=\text { wkrprfm }_{i t}+\text { avedist }_{i t}+\text { L. }_{\text {wagediff }}
$$

The third regression at Table 4 brings in L.wagediff, the lagged variable of the wagediff in the first stage of the regression.

$$
\text { Cream }_{i}=\text { wkrprfm }_{i t}+\text { avedist }_{i t}+\text { wagedifva }_{i t}
$$

The fourth regression added the actual wage difference at the pre-program period which equals to current year wage minus last year wage in 2002 and 2003, respectively.

The first regression at Table 4 shows the OLS results that the training effect is insignificant and is similar to the effects at Table 2. However, the "cream-skimming" effect is significantly different from zero. As discussed before, the OLS results may be biased by self selection. The second and the forth regression therefore show both training and cream-skimming effect are positively significant on all IV regressions, while the training effects on income is reduced after the introduction of "cream-skimming." This is a reasonable result since the training effect at Table 3 did not have any control over the problem of creamskimming. For example, take the Training coefficient of column one at Table 3 and compare with the same IV regression with cream-skimming at column two at Table 4, the training coefficient drop from 1.13 to 0.88 ; it is a 22 percent drop in the training effect after controlled for the cream-skimming effect!

When comparing the tests on these IV regressions, the IV using L.wagediff cannot reject the redundancy test, suggesting that the inclusion of this IV does not increase the model's explanation power. While both 
the IV regression using wagediff and wagedifva show significant explanation power at the first stage regression, the IV the wagedifva cannot reject the Weak identification test. The only IV regression which passed all the tests is the second regression which uses wagediff as IV. If we accept this result, the interpretation could be since "cream-skimmers" at rural area are those who have higher ability and may have somewhat higher income than average. However, as shown in Figure 1, their average income may not be overwhelmingly high, due to the constraint of rural setting and choice of job of rural migrant. Following this logic, a drop in wage could well enough induce these "cream-skimmers" to enter the program. Although, the cream-skimming effect is significant, the training effect has also similar positive effect on income change, according to the coefficients at second regression at Table 4. Furthermore, the wage drop may not constitute a reduction of "opportunity cost" at the rural labor training program because firstly, unlike the case at Ashenflter, the training duration is short (usually around 1-2 weeks) for this rural labor training program. Secondly, the sunshine program is a government funded training program in which the labor essentially does not incur any cost of training. Thus, instead of "opportunity cost" argument, there may well be the "career concern" argument that a wage drop may signify dropping of labor competitiveness and induce labor to enter training program. Also, the government will issue graduation certification after their training and that helps to signify their ability. 
Table 4: Instrumental Variable Regression on Training and "cream-skimming" Effect to Wage Change

\begin{tabular}{|c|c|c|c|c|c|c|c|c|}
\hline & (1) & & (2) & & (3) & & (4) & \\
\hline In (hourly wage) & Coef. & $\mathrm{P}>|\mathrm{t}|$ & Coef. & $\mathrm{P}>|\mathrm{t}|$ & Coef. & $\mathrm{P}>|\mathrm{t}|$ & Coef. & $\mathrm{P}>|\mathrm{t}|$ \\
\hline Training, $(0=$ non-trained $)$ & $\begin{array}{l}-0.06 \\
(0.06)\end{array}$ & 0.32 & $\begin{array}{c}0.88 \\
(0.24)\end{array}$ & 0.00 & $\begin{array}{c}0.86 \\
(0.35)\end{array}$ & 0.02 & $\begin{array}{c}0.86 \\
(0.16)\end{array}$ & 0.00 \\
\hline Cream-skimming ( 1 = pre-program wage $>$ average wage) & $\begin{array}{c}0.58 \\
(0.05)\end{array}$ & 0.00 & $\begin{array}{c}0.89 \\
(0.32)\end{array}$ & 0.01 & $\begin{array}{c}0.43 \\
(0.43)\end{array}$ & 0.32 & $\begin{array}{c}0.95 \\
(0.14)\end{array}$ & 0.00 \\
\hline Migrant gender, $(0=$ female $)$ & $\begin{array}{c}0.39 \\
(0.06)\end{array}$ & 0.00 & $\begin{array}{c}0.48 \\
(0.07)\end{array}$ & 0.00 & $\begin{array}{c}0.45 \\
(0.09)\end{array}$ & 0.00 & $\begin{array}{c}0.47 \\
(0.06)\end{array}$ & 0.00 \\
\hline Migrant age & $\begin{array}{c}0.02 \\
(0.02)\end{array}$ & 0.26 & $\begin{array}{l}-0.03 \\
(0.02)\end{array}$ & 0.13 & $\begin{array}{l}-0.03 \\
(0.02)\end{array}$ & 0.19 & $\begin{array}{l}-0.04 \\
(0.02)\end{array}$ & 0.03 \\
\hline Migrant age square & $\begin{array}{c}0.00 \\
(0.00)\end{array}$ & 0.36 & $\begin{array}{c}0.00 \\
(0.00)\end{array}$ & 0.06 & $\begin{array}{c}0.00 \\
(0.00)\end{array}$ & 0.13 & $\begin{array}{c}0.00 \\
(0.00)\end{array}$ & 0.01 \\
\hline Migrant marital status ( $0=$ single $)$ & $\begin{array}{c}0.11 \\
(0.05)\end{array}$ & 0.04 & $\begin{array}{c}0.03 \\
(0.06)\end{array}$ & 0.69 & $\begin{array}{c}0.02 \\
(0.06)\end{array}$ & 0.79 & $\begin{array}{c}0.02 \\
(0.05)\end{array}$ & 0.73 \\
\hline Migrant education (year) & $\begin{array}{c}0.06 \\
(0.01)\end{array}$ & 0.00 & $\begin{array}{c}0.10 \\
(0.02)\end{array}$ & 0.00 & $\begin{array}{c}0.10 \\
(0.02)\end{array}$ & 0.00 & $\begin{array}{c}0.10 \\
(0.01)\end{array}$ & 0.00 \\
\hline Migration experience (year) & $\begin{array}{c}0.01 \\
(0.01)\end{array}$ & 0.09 & $\begin{array}{c}0.02 \\
(0.01)\end{array}$ & 0.01 & $\begin{array}{c}0.03 \\
(0.01)\end{array}$ & 0.02 & $\begin{array}{c}0.02 \\
(0.01)\end{array}$ & 0.00 \\
\hline Constant & $\begin{array}{c}0.09 \\
(0.42)\end{array}$ & 0.83 & $\begin{array}{c}0.41 \\
(0.41)\end{array}$ & 0.31 & $\begin{array}{l}0.36 \\
(0.46)\end{array}$ & 0.44 & $\begin{array}{c}0.07 \\
(0.35)\end{array}$ & 0.85 \\
\hline Number of obs & 424 & & 289 & & 214 & & 287 & \\
\hline Centered R-squared & 0.52 & & 0.25 & & 0.34 & & 0.26 & \\
\hline Un-centered R-squared & 0.50 & & 0.91 & & 0.92 & & 0.91 & \\
\hline Root MSE & 0.55 & & 0.45 & & 0.42 & & 0.45 & \\
\hline \multirow[t]{3}{*}{ IV instruments: Training } & OLS & wkrprfm & $\begin{array}{c}0.41 \\
(0.10)\end{array}$ & wkrprfm & $\begin{array}{c}0.42 \\
(0.12)\end{array}$ & wkrprfm & $\begin{array}{c}0.42 \\
(0.10)\end{array}$ & \\
\hline & & avedist & $\begin{array}{l}-0.02 \\
(0.00)\end{array}$ & avedist & $\begin{array}{l}-0.02 \\
(0.01)\end{array}$ & avedist & $\begin{array}{l}-0.02 \\
(0.00)\end{array}$ & \\
\hline & & wagediff & $\begin{array}{c}0.00 \\
(0.06)\end{array}$ & L. wagediff & $\begin{array}{c}0.04 \\
(0.07)\end{array}$ & wagedifva & $\begin{array}{c}0.01 \\
(0.01)\end{array}$ & \\
\hline \multirow[t]{3}{*}{ IV instruments: Cream-skimming } & & wkrprfm & $\begin{array}{c}0.27 \\
(0.10)\end{array}$ & wkrprfm & $\begin{array}{c}0.41 \\
(0.13)\end{array}$ & wkrprfm & $\begin{array}{c}0.27 \\
(0.10)\end{array}$ & \\
\hline & & avedist & $\begin{array}{c}0.01 \\
(0.01)\end{array}$ & avedist & $\begin{array}{c}0.01 \\
(0.01)\end{array}$ & avedist & $\begin{array}{c}0.00 \\
(0.01)\end{array}$ & \\
\hline & & wagediff & $\begin{array}{l}-0.27 \\
(0.06)\end{array}$ & L. wagediff & $\begin{array}{c}0.03 \\
(0.12) \\
\end{array}$ & wagedifva & $\begin{array}{c}0.11 \\
(0.03)\end{array}$ & \\
\hline \multicolumn{9}{|l|}{ Ramsey test: (Ho: model has no omitted variables) } \\
\hline $\begin{array}{l}F(3,396) \\
\text { Prob }>F\end{array}$ & \multicolumn{8}{|l|}{$\begin{array}{l}0.55 \\
0.65\end{array}$} \\
\hline \multicolumn{9}{|l|}{ Underidentification tests: } \\
\hline \multicolumn{2}{|l|}{ Chi-square statistic } & & $\begin{array}{c}10.46 \\
0.01\end{array}$ & & $\begin{array}{l}5.35 \\
0.07\end{array}$ & & $\begin{array}{c}14.35 \\
0.00\end{array}$ & \\
\hline \multicolumn{9}{|l|}{$\begin{array}{l}\text { P-value } \\
\text { Cragg-Donald test of underidentification: } \mathrm{H} 0=\text { (underidentified) }\end{array}$} \\
\hline \multicolumn{3}{|l|}{ Chi-square statistic } & 10.65 & & 5.42 & & 5.37 & \\
\hline \multicolumn{3}{|l|}{ P-value } & 0.01 & & 0.07 & & 0.07 & \\
\hline \multicolumn{3}{|l|}{ LR IV redundancy test: (Instruments tested) } & wagediff & & L.wagediff & & wagedifva & \\
\hline \multicolumn{3}{|l|}{ Chi-square statistic } & 5.90 & & 0.16 & & 12.85 & \\
\hline \multicolumn{3}{|l|}{$\begin{array}{l}\text { P-value } \\
\text { Hansen J statistic: (overidentification test of all instruments) }\end{array}$} & 0.05 & & 0.93 & & 0.00 & \\
\hline \multicolumn{3}{|l|}{$\begin{array}{l}\text { Hansen J statistic: (overidentification test of all instruments) } \\
\text { Chi-square statistic }\end{array}$} & 0.00 & & 0.24 & & 0.32 & \\
\hline P-value & & & 0.97 & & 0.63 & & 0.57 & \\
\hline Shea's partial R2 test of instrument strength: & & & & & & & & \\
\hline Train: F-statistic & & & 8.84 & & 6.07 & & 9.05 & \\
\hline P-value & & & 0.00 & & 0.00 & & 0.00 & \\
\hline Cream-skimming: F-statistic & & & 7.96 & & 3.22 & & 2.09 & \\
\hline P-value & & & 0.00 & & 0.02 & & 0.04 & \\
\hline Weak identification statistics: & & & & & & & & \\
\hline Cragg-Donald (N-L)*minEval/L2 F-stat & & & 3.25 & & 1.61 & & 1.64 & \\
\hline Anderson-Rubin test : $(\mathrm{H} 0=$ endogenous regressors are joi & equal to & zero) & & & & & & \\
\hline Chi-square statistic & & & 26.22 & & 14.82 & & 26.73 & \\
\hline P-value & & & 0.00 & & 0.00 & & 0.00 & \\
\hline
\end{tabular}




\section{Conclusion:}

Using instrumental regressions on the data collected from a pilot study of the "sunshine program" at Zhejiang province, this paper provides a way to look at both training and cream-skimming effect in a rural labor training program. This paper shows that the self selection of laborers to participate in the training program may be affected by the availability of active labor in a family and transaction cost to training center. The instrumental regressions also show that, after correcting the selection problem to training program, training has positive impact on wage change. Furthermore, this paper shows that pre-program wage drop may not have a direct effect on the labor's participation in a training program in general. This is consistent with the findings of Heckman and Smith (1999), who used experimental impact estimation on multiple periods of before-after earning to test the pre-program earnings dip effect on the determinant of Participation in a Social Program. Their basic conclusion is that pre-program Earnings Dip is not a determinant to program participation. This paper’s findings also echo Heckman and Smith's argument that prior models emphasized on "opportunity cost of earning” as a major determinant of an individual's participation into a labor training program may need to be revised (Heckman and Smith, 1999: 345). In fact, the setting of the rural labor training may be very different from other training. Firstly, the duration of training is short. Secondly, the government has funded the program. Thirdly, the income among rural labor is generally low, even the proportion of difference between groups may be high. A drop in wage may already warrant attention to rural family even in the high income group. Thus, the "opportunity cost" argument may work in the rural labor training setting. Instead, a pre-program wage drop for a rural labor training program may induce the higher ability workers to take advantage of the training program and earn higher income. The motivation of this action may be a concern for career which is very different from the opportunity cost perspective. A career concern perspective argues when a drop of wage at the pre-program period may worry the worker for future income. Thus this paper shows that the "cream-skimming" effect may coexist with the training effect to explain the income change. This suggests the monitoring and the trainees' targeting may be a problem and may cause a waste of resource to train the higher caliber workers. 
Putting the cream-skimming effect and the training issues together, a better accountability and governance of the training program which actively takes into account of rural laborer needs may be called for. ${ }^{7}$ Having said, this study is very small in scale and cannot provide general answers to bigger questions. A study on a much larger scale is called for if we want to investigate the "scale-up" effects of the training program. Furthermore, a more detailed analysis is needed to look into different interactions such as gender wage gap and education cohort effect in training programs.

\section{Reference:}

Agricultural Department, PRC, (2005a) nong cun lao dong li zhuan yi pei xun cai zheng bu zhu zi jin guan li ban fa (The Financial Management of the Sunshine Program) Online. Available at HTTP: http://www.nmpx.gov.cn/yangguanggongcheng/xiangmuguanli/default.htm (accessed January 25, 2006)

Agricultural Department, PRC, (2005b) nong cun lao dong li zhuan yi pei xun yang guang gong cheng xiang mu jian cha yan shou ban fa (shi xing) 2005-06-15 (The Temporary Role for Evaluation Method of the Sunshine Program). Online. Available at HTTP:

http://www.nmpx.gov.cn/yangguanggongcheng/xiangmuguanli/default.htm (accessed January 25, 2006)

Agricultural Department, PRC, (2004) yang guang gong cheng jian (A Simple Description of the Sun Shine Program), Online. Available at HTTP: http://www.nmpx.gov.cn/yangguanggongcheng/gongchengjieshao/t20040331_16323.htm. (accessed 13 August 2004).

Angrist, Joshua D. and W. Evans. (1998) “Children and Their Parents' Labor Supply: Evidence from Exogenous Variations in Family Size.” American Economic Review 88(3): 450-477.

Ashenfelter, Orley. (1978) "Estimating the Effect of Training Programs on Earnings." Review of Economics and Statistics 60: 47-57.

Ashenfelter, Orley and D. Card. (1985) "Using the longitudinal Structure of Earnings to Estimate the effect of Training Programs.” Review of Economics and Statistics 67: 648-60.

Autor, David H. (2001) “Wiring the Labor Market.” Journal of Economic Perspectives 15(1): 25-40.

Autor, David H. and Susan N. Houseman (2005) "Do Temporary Help Jobs Improve Labor Market Outcomes for Low-Skilled Workers? Evidence from Random Assignments.” Memo, MIT Economics Department.

Betcherman, Gordon, Amit Dar, Amy Luinstra, Makoto Ogawa (2000) “Active Labor Market Programs: Policy Issues for East Asia,” World Bank Social Protection Discussion Paper No. 5.

\footnotetext{
${ }^{7}$ For a detail analysis of the governance and implementation issues for the rural labor training program please see Chen (2007, 2008).
} 
Chen, Yiu Por (2007) "Rural Labor Training in China: Issues on Policy Implementation at Village Level.” IDREC-CERDI Newsletter

Chen, Yiu Por (2008) "The Rural Labor Training in China: Program Implementation and Monitoring Issues.” Unpublished Memo.

Culver, Ells (2003) “Poverty Alleviation Through Microfinance in China,”

Global Envision, February 06, 2003. Online. Available at HTTP:

http://www.globalenvision.org/library/4/140/ (accessed July 28, 2006)

Dar, Amit (2002) Impact Evaluation: Techniques for Evaluation Active Labor Market Programs. World Bank Employment Policy Primer, No. 2, December 2002.

Dar, Amit and P. Zafiris Tzannatos (1999): Active Labor Market Programs: A Review of the Evidence Based on Evaluations. Social Protection Discussion Paper 9901. Washington, D.C.: World Bank

Fay, Robert G. (1996) "Enhancing the Effectiveness of Active Labor Market Policies

Evidence from Programme Evaluations in OECD Countries," OECD Labor Market and Social Policy Occasional Papers, No. 18, OECD Publishing.

Friedlander, Daniel, David H. Greenberg, and Philip K. Robins. (1997) "Evaluating Government Training Programs for the Economically Disadvantaged.” Journal of Economic Literature 35 (4) pp. 1809-1855

Gill, I, F. Fluitman, and A. Dar (2000) Vocational Education and Training Reforms: Matching Skills to Market and Budget. Oxford University Press.

Heckman, James. (1978) "Dummy Endogenous Variables in a Simultaneous Equations System." Econometrica 46: 931-59.

Heckman, James and Robb, Richard. (1985) "Alternative methods for Evaluating the Impact of Inteventions.” In Jeames Heckman and Burton Singer (eds.) Longitudinal Analysis of Labor Market Data. Cambridge: Cambridge University Press. pp. 156-245.

Heckman, J., J. Smith. (1999) "The Pre-program Earnings Dip and the Determinats of Participation in a Social Program: Implications for Simple Program Evaluations Strategies.” Economic Journal 109: 313-348.

Lewis, W. Arthur. (1954) “Economic Development with Unlimited Supplies of Labor.” Manchester School of Economic and Social Studies 22: 139-91.

Li Binglong (2002) “The Progress of Poverty Alleviation in China: Experience, Problems and Implications for the Asia-Pacific" paper presented at Paper for the Meeting of the Advisory Panel on ESCAP/UNDP initiative to support the achievement of Millennium Development Goals in Asia and the Pacific Region, February 2002, Bangkok.

Lundin, Martin and Per Skedinger (2006) "Decentralisation of active labor market policy: The case of Swedish local employment service committees,” Journal of Public Economics, 90(4-5), May 2006, pp. 775798.

O’Leary, Christopher, Alena Nesporova, Alexander Samorodov (2001) Manual of Evaluation of Labor Market Policies in Transition Economies,” International Labor Organization, Geneva.

Qian, Tian (2005) "Study critiques poverty alleviation funding, suggests new policies," China Development Brief Online. Available at HTTP: http://www.chinadevelopmentbrief.com (accessed 03 August 2006)

State Statistical Bureau (SSB) (2002) China Statistical Yearbook 2002, Statistical Publisher. 
Technical Education Division, Agricultural Department, PRC, (2004) nong ye bu ke ji jiao yu si(2004)guan yu shi xing nong cun lao dong li zhuan yi pei xun yang guang gong cheng yue bao tong ji de tong zhi nong ke (jiao) han [2004] 51 hao 2004 nian 7 yue 30 ri (memo on the implementation of the Sunshine Program’ s monthly report statistics, letter(2004) number 51, July $30^{\text {th }} 2004$ )

Zhong Guo xin nong weng (agricultural development website) (2004) yang guang gong cheng pei xun nong cun lao dong li 133 wan ren 95 wan ren shi xian le jiu ye zhuan yi (1.13 million rural labor force trained under the Sunshine program, in which, 95 million successfully transfer to other sectors) Online. Available at HTTP: http://www.cnan.gov.cn/cnan/ (accessed 07 January 2005).

Zhu Ling and Jiang Zhongyi (1996) Public Works and Poverty Alleviation in Rural China Commack, NY: Nova Science Publishers, 1996.

World Bank Labor Issues in Infrastructure Reform: A Toolkit Online. Available at HTTP: http://rru.worldbank.org/Documents/Toolkits/Labor/Toolkit/index.html (accessed 07 January 2005).

Appendix A: supplementary descriptive statistics of the survey data

I first start with some basic observations from our survey to see the basic pattern of the training programs and its consistency with the central government's goals in section 3. Our survey shows that 44 households reported received training in 2003 and 2004 (when the pilot program of the Sunshine program began).

Table A1: Distribution of Respondent in the Survey of Six Villages

\begin{tabular}{ccc} 
village label & Freq. & Percent \\
\hline 11 & 57 & 10.88 \\
12 & 51 & 9.73 \\
13 & 49 & 9.35 \\
21 & 43 & 8.21 \\
22 & 35 & 6.68 \\
23 & 39 & 7.44 \\
\hline Total & 274 & 100
\end{tabular}

Over 50 percent of our respondents are trained to be domestic helper, while around 20 percent of them received training in computer literacy training. In fact, majority of the job category are low skill oriented (For detailed breakdown of training categories, please see Table A2.). Corresponding with the low skill job nature, the training periods are tended be short. 
Table A2: Job Training Catergory

\begin{tabular}{lcc} 
Training catergory & Freq. & Percent \\
\hline gardener & 1 & \\
computer & 9 & 2.33 \\
electronic & 1 & 20.93 \\
garment & 2 & 2.33 \\
domestic helper & 22 & 4.65 \\
driver & 2 & 51.16 \\
cement work & 1 & 4.65 \\
electric & 4 & 2.33 \\
others & 1 & 9.3 \\
\hline Total & 43 & 2.33 \\
\hline
\end{tabular}

The training periods are short which is consistent to the purpose of the low skill training program. As illustrated in Table A3, 68 percent of training finished within two weeks. The survey also shows that, similar to the description of the central government statement, the training costs are usually covered by the local governments. At Table A4, 88 percent of respondent received training for free. These two tables support the claim in this paper that the opportunity cost of forgone wage is low.

Table A3: Dates Spent on Training

\begin{tabular}{ccc} 
Dates in Training & Freq. & Percent \\
\hline 1 & 2 & 4.55 \\
2 & 3 & 6.82 \\
2.5 & 1 & 2.27 \\
3 & 8 & 18.18 \\
5 & 1 & 2.27 \\
7 & 2 & 4.55 \\
10 & 2 & 4.55 \\
12 & 2 & 4.55 \\
15 & 9 & 20.45 \\
18 & 3 & 6.82 \\
20 & 9 & 20.45 \\
30 & 1 & 2.27 \\
50 & 1 & 2.27 \\
\hline Total & 44 & 100 \\
\hline
\end{tabular}

RE: the job needs 30 days training is the computer literacy training; the job needs 50 days training is driving 
Table A4: Training Fee that Needed to Pay:

\begin{tabular}{lcc} 
a8106 & Freq. & Percent \\
\hline 0 & 37 & 88.1 \\
100 & 1 & 2.38 \\
200 & 2 & 4.76 \\
2600 & 1 & 2.38 \\
3600 & 1 & 2.38 \\
\hline Total & 42 & 100 \\
\hline
\end{tabular}

RE: 2600 and 3600 are driver trainees of driving course

Another concern is the selectivity of trainee. Although the Sunshine Program regulations stated clearly that training results should be publicly available at county level (Agricultural Department, 2005a), information about training program dissemination at the village level is usually through the leaders at the village. The usual way is face to face distribution or through broadcasting. Without proper labor training and labor market information, peasants may not be able to demand the training. In fact, as shown in Table A5, over 43 percent of our respondent received labor training information from government, while around 40 percent of them received the information from other channels. Thus, the preliminary observation of the training program seems consistent with the central government's goal at section 3.

Table A5: Through which channel did you learn about the program?

\begin{tabular}{lcc} 
Channel & Freq. & Percent \\
\hline government & 19 & 43.18 \\
boardcasting & 4 & 9.09 \\
relatives & 1 & 2.27 \\
friends & 1 & 2.27 \\
villagers & 1 & 2.27 \\
others & 18 & 40.91 \\
\hline Total & 44 & 100 \\
\hline
\end{tabular}

